Review

\title{
Free fatty acid receptors (FFARs) in adipose: Physiological role and therapeutic outlook.
}

\author{
Saeed Al Mahri ${ }^{1}$, Shuja Shafi Malik ${ }^{1}$, Maria Al Ibrahim ${ }^{1}$, Esraa Haji ${ }^{1}$, Ghida Dairi ${ }^{1,2,3}$ and Sameer Mohammad ${ }^{1 *}$ \\ 1 Affiliation 1; Experimental Medicine, King Abdullah International Medical Research Center (KAIMRC), \\ King Saud Bin Abdulaziz University for Health Sciences (KSAU-HS), Ministry of National Guard Health \\ Affairs (NGHA), Riyadh, Saudi Arabia. \\ 2 Physiology Department, College of Medicine,King Saud University, Riyadh, Saudi Arabia \\ 3 Deanship of Scientific Research, Umm Al-Qura University, Makkah, Saudi Arabia. \\ *Correspondence: mohammadsa1@ngha.med.sa.
}

\begin{abstract}
:
Fatty acids (FFAs) are important biological molecules that serve as a major energy source and are key components of biological membranes. Besides, FFAs play important roles in metabolic regulation and contribute to the development and progression of metabolic disorders like diabetes. Recent studies have shown that FFAs can act as important ligands of G-protein coupled receptors (GPCRs) on the surface of cells and impact key physiological processes. Free fatty acid activated receptors include FFAR1 (GPR40), FFAR2 (GPR43), FFAR3 (GPR41) and FFAR4 (GPR120). FFAR2 and FFAR3are activated by short chain fatty acids like acetate, propionate and butyrate whereas FFAR1 and FFAR4 are activated by medium and long chain fatty acids like palmitate, oleate, linoleate and others. FFARs have generated considerable attention over the last few years and have become attractive pharmacological targets in the treatment of type 2 diabetes and metabolic syndrome. Several lines of evidence point to their importance in the regulation of whole-body metabolic homeostasis including adipose metabolism. Here we summarize our current understanding of the physiological functions of FFAR isoforms in adipose biology and explore the prospect of FFAR based therapies to treat patients with obesity and Type 2 Diabetes.
\end{abstract}

Keywords: Adipose tissue; G-protein coupled receptors; Free Fatty acid receptors; Thermogenesis; Adipogenesis

\section{Introduction}

Free Fatty acids (FFAs) play a vital role as energy substrates and form key components of cellular membranes. Diet is main source of long- and medium- chain free fatty acids whereas short chain fatty acids are produced as a result of bacterial fermentation process in the gut. Over the past few years FFAs have emerged as important signaling molecules in the regulation of metabolic homeostasis. FFAs have been shown to activate cell surface receptors known as Free Fatty Acid Receptors (FFARs). FFARs belong to the family of G-Protein Coupled Receptors (GPCRs) that signal via the activation of heterotrimetric G-Protein complex. GPCRs are characterized by signature seven transmembrane domains, an extracellular N-terminus and an intracellular C-terminus [1,2] Around 800 GPCRs have been identified in man, of which about more than half have sensory functions including olfactory (391), Vision (10), taste (33) and pheromone receptors [1,3,4]. The remaining 356 non-sensory GPCRs mediate signaling of a variety of ligands ranging from small molecules and metabolites to peptides and large proteins [5]. Free Fatty acids have also been shown to activate signaling cascades involving GPCRs. Till date four FFARs have been identified that act as ligands for FFAs based on their chain length. FFAR1 
(GPR40) and FFAR4 (GPR120) are activated by long-chain fatty acids like Palmitate, Oleate and Linoleate whereas FFAR2 (GPR43) and FFAR3 (GPR41) are mainly activated by short chain fatty acids like acetate, butyrate and propionate [6-9]. FFARs are widely expressed throughout the human body and have been shown to regulate multiple biological processes. FFAR mediated signaling has been implicated in metabolic processes like insulin secretion from pancreatic beta cells, incretin secretion from entero-endocrine cells, regulation of food intake, adipose tissue biology and many more $[6,7,10-13]$. These receptors are considered attractive therapeutic targets for metabolic disorders like obesity and type 2 diabetes. In fact several agonist of FFARs have been developed and tested in animal models as well in human trials [14-17]. Here we focus on the role of FFARs in regulating various aspects of adipose biology including adipogenesis, lipid and glucose metabolism, and explore the prospect of FFAR based therapies to treat patients with metabolic disorders

\section{FFAR2 and FFAR4 are highly expressed in adipose tissue}

FFARs are expressed in almost all tissues including those that play key roles in metabolic homeostasis. FFAR1 is highly expressed in pancreatic $\beta$ cells, central nervous system, Entero-endocrine cells and several other tissues [18-23]. FFAR1 has been extensively studied for its role in pancreatic $\beta$-cell metabolism and FFAR1 agonists have attracted considerable attention as potential anti-diabetic agents $[13,24]$. However, FFAR1 expression has not been reported in human or mouse adipose tissue. FFAR2 is widely expressed in enteroendocrine cells, pancreatic $\beta$ cells, and immune cells. Both mouse and human adipose tissue abundantly express FFAR2 $[25,26]$. On the other hand FFAR3 is expressed in pancreatic $\beta$ cells, immune cells, central nervous system and enteroendocrine cells [8,27-29]. However, FFAR3 is not expressed in human or mouse adipose tissue or in adipocytes. FFAR4 is highly expressed in both human and mouse adipose tissue. In addition, FFAR4 is also expressed in pancreatic $\beta$ cells, liver and immune cells [30-32]. Fig. 2 summarizes the expression of FFAR isoforms in various tissues.

\section{Role of FFAR2 in adipose metabolism and energy homeostasis}

Numerous studies have demonstrated that FFAR2 is expressed in human and mouse white adipose tissue (WAT) and also in murine adipocyte cell line 3T3L1 [33-35]. Hong et al. reported that FFAR2 was highly expressed in adipocytes, with a much lower expression in stromal-vascular cells [34]. Besides, FFAR2 expression was upregulated during the adipogenic differentiation of 3T3L1 cells. The authors also observed that FFAR2 expression was elevated in adipose tissue of high fat diet mice prompting them to explore the role of FFAR2 in the adipogenic process. The authors demonstrated that natural agonists of FFAR2, acetate and propionate promote the adipogenesis process and this effect was mediated by FFAR2. On the contrary, Dewulf et al reasoned that FFAR2 was not involved in human adipogenesis based on their observation that FFAR2 expression was not unregulated in white adipose of obese individuals and inability of FFAR2 agonists to induce differentiation of human pre-adipocytes into mature adipocytes [36]. This assessment was strengthened by another study, which showed that propionate or acetate have no significant effect on adipogenesis in 3T3-L1 cells [37]. The authors demonstrated that FFAR2 is not expressed until approximately $48 \mathrm{~h}$ into the differentiation process of 3T3 L1 adipocytes and supplementing differentiation cocktail with acetate or propionate didn't have any effect on the differentiation process. Yet another study by Ivan et al showed that FFAR2 had an inhibitory role in adipogenic differentiation of human Mesenchymal Stem cells (MSCs) [38]. The authors reported that propionate and a synthetic agonist of FFAR2 suppressed adipogenic differentiation and this effect was mediated by FFAR2. In total, the role of FFAR2 in adipogenesis is still a matter of debate and more studies on both human and murine adipocytes are needed to get a clearer picture of involvement of FFAR2 in adipogenesis. 
While, the impact of FFAR2 on adipogenesis is still unclear, many studies have shown that FFAR2 activation is associated with inhibition of lipolysis. Using murine adipocyte cell line 3T3 L1, Hong et al demonstrated that acetate and propionate inhibited isoproterenol induced lipolysis and this effect was abolished in FFAR2 deficient adipocytes [34]. Another study confirmed the anti-lipolytic activity of FFARs in both 3T3L1 adipocytes as well in primary adipocytes [33]. The authors further showed that in vivo infusion of acetate reduced the circulating free fatty acid levels in mice. The anti-lipolytic effect of acetate was completely absent in FFAR2 knockout mice supporting the role of FFAR2 in this process. Lee et al also demonstrated that acetate suppressed lipolysis in 3T3 L1 adipocytes in a dose dependent manner [39]. FFAR2 specific synthetic agonist developed by Wang et al inhibited lipolysis via the activation of FFAR2 in murine adipocytes [40]. This synthetic agonist reduced circulating Free Fatty acid levels when administered to mice. Several other synthetic agonists of FFAR2 have been shown to inhibit lipolysis in adipocytes.

The effect of FFAR2 on adipose insulin sensitivity and whole body metabolic homeostasis has been the subject of several independent studies but the results are inconclusive [41]. Two independent studies point to a positive role played by FFAR2 in the regulation of metabolic homeostasis. The authors used FFAR2 knockout mice to show that loss of FFAR2 results in dysregulated metabolic homeostasis and reduced insulin sensitivity. Adipose specific FFAr2 overexpression was associated with improved insulin signaling and glucose tolerance [42,43]. Conversely, Bjursell et al studied the effect of FFAR2 in lipid and energy metabolism by using FFAR2 knockout animals. The authors showed that the loss of FFAR2 was not associated with any metabolic abnormality in mice fed a normal diet. Interestingly, FFAR2 knockout mice were protected from HFD-induced obesity and metabolic abnormalities suggesting a negative influence of FFAR2 on metabolic homeostasis [44]. The reasons for discrepancy in the outcome of studies on FFAR2 knockout mice are unclear but could be due to different genetic background of mice. Bjursell et al. [44] used C57BL/6 mice for their study whereas both Tolhurst et al. [42] and Kimura et al. [43] used 129/SvEv background mice

Overall, FFAR2 appears to have considerable functional significance in adipose tissue metabolism and whole body energy homeostasis but more work is needed to address the inconsistencies reported by different research groups.

\section{Role of FFAR4 (GPR120) in adipogenesis and adipose metabolism}

Multiple lines of evidence suggest that FFAR4 plays a critical role in adipose tissue metabolism. First, FFAR4 is highly expressed in adipocytes and adipose tissues and shows a marked increase in expression during the adipogenic differentiation of murine and human pre-adipocytes $[45,46]$. Second, mice deficient in FFAR4 are more likely to develop obesity, metabolic dysregulation and develop insulin resistance and increased inflammation in adipose tissue [45,47]. In 3T3L1 adipocytes forced reduction of FFAR4 using siRNA was shown to inhibit differentiation and lipid accumulation. In addition downregulation of FFAR4 also led to impaired of insulin signaling via reduction of Glucose transporter (GLUT4) and Insulin receptor substrate (IRS) expression [48]. On the other hand activation of FFAR4 by specific agonists has been found to promote adipocyte differentiation [49]. Moreover, treatment of obese/ insulin resistant mice with specific agonist of FFAR4 results in improved glucose tolerance, enhanced insulin sensitivity and reversal of metabolic abnormalities [50]. FFAR4 is also highly expressed in brown fat (BAT) and is upregulated in mice exposed to cold. The activation of FFAR4 leads to increased thermogenesis via increased expression of BAT specific markers including uncoupling protein 1 (UCP1) [49,51,52]. In addition, FFAR4 knockout mice have impaired browning of subcutaneous WAT in response to a cold exposure [52] . Moreo- 
ver, FFAR agonists have been shown to increase fatty acid uptake and oxidation, augment mitochondrial respiration and reduce fat mass in mice [53,54]. A recent study demonstrated that induction of FFAR4 signaling elevated the level of the circulating FGF21, and therefore, enhanced BAT activities and browning of WAT in mice [55]. Furthermore, a study showed that FFAR4- KO neonates' mice had reduced activity of neonatal BAT and inhibition of thermogenesis leading to reduction UCP1 expression, fatty acid oxidative capacity and the circulating levels of fibroblast growth factor 21 (FGF21). Therefore, FFAR4-null mice had cold intolerance after birth and their survival impacted [52]. Third, in humans the expression of FFAR4 are significantly higher in adipose tissue of obese subjects compared to lean healthy ones [45]. In addition, a deleterious variant of FFAR4 $(\mathrm{R} 270 \mathrm{H})$ is associated with increased risk of obesity and increased fasting glucose levels in human subjects of European origin [45,56]. R270H FFAR4 variant has also been shown to acts together with dietary fat intake to modulate the risk of type 2 diabetes [57]. Clinic, in vivo and in vitro evidence in support of importance of FFAR4 in adipose metabolism is summarized in Fig.

\section{FFAR agonists in the treatment of metabolic diseases}

Even since the members of FFAR family were de-orphanized, their role in different biological processes have been extensively studied. In particular, their contribution to the metabolic and energy homeostasis has been comprehensively recognized and they have attracted considerable attention in the drug discovery field [58,59]. As a results, several ligands of FFARs have been developed for the purpose of using them a therapeutic drugs for metabolic diseases like diabetes and obesity. The list of synthetic ligands of FFAR and their physiological functions are summarized in Table 1. Out of the four isoforms FFAR1 has emerged the most targeted receptor of this family. Several ligands targeting FFAR1 have been developed and functionally validated in preclinical in vitro and in vivo studies, and some of them have even reached human clinical trials. The most advanced FFAR1 R agonist that reached human clinical trials is TAK-875 developed by Takeda. TAK-875 had shown promising efficacy and significantly reducing $\mathrm{HbA} 1 \mathrm{C} \mathrm{lev-}$ els without causing any hypoglycemic episodes. However, during phase 2 clinical trials the compound was found to cause liver toxicity and further development of the drug was discontinued $[60,61]$. Efforts are on to develop safer alternatives with good efficacy and with no or little toxicity $[16,20,62]$.

Synthetic ligands of FFAR2 has also been developed and evaluated for their therapeutic efficacy in preclinical studies. The first FFAR2 specific agonist, (2S)-2-(4-chlorophenyl) N-(5-fluoro-1,3-thiazol-2-yl)-3-methylbutanamide (CMTB) was discovered by Lee, et al [39]. CMTB was able to inhibit cAMP formation with higher potency than acetate and propionate in $\mathrm{CHO}$ cells stably expressing FFAR2. In addition, CMTB inhibited lipolysis in 3T3 L1 adipocytes in a dose dependent manner through the activation of Gai pathway. Subsequently, after detailed investigation of the pharmacology of CMTB the binding site on FFAR2 was found to be distinct from the endogenous ligands. In addition, the signaling responses to CMTB at FFAr2 were not identical to those of endogenous SCFAs [63]. Therefore, there is a need to develop FFAR2 agonists that have biochemical properties similar to the endogenous ligands of FFAR2. Hudson et al described 3-benzyl-4-(cyclopropyl-(4-(2,5-dichlorophenyl)thiazol-2-yl)amino)-4-oxobutanoic acid (compound1) as a highly potent and selective ortho-ateric ligand of FFAR2. Compound 1 was shown to inhibit lipolysis in both human and murine adipocyte cell lines. In addition, Compound 1 stimulates GLP-1 Release from murine STC-1 enteroendocrine cells [64]. Hansen et al described TUG-1375 as a potent agonist of FFAR2 with favorable pharmacokinetic properties [65]. TUG-1375 was able to inhibit isoproterenol induced lipolysis in murine adipocytes with a 50-fold more potency as compared to the natural agonist of FFAR2, propionate. None of these ligands have undergone preclinical or clinic trials but these compounds have huge potential to serve as useful tools to study FFA2 function 
and help in the development of future ligands at FFAR2 with tremendous therapeutic potential [64].

FFAR4 has attracted considerable attention from the pharmaceutical industry due to its multiple functions in metabolic homeostasis. A number of FFAR4 specific ligands have been developed to study FFAR4 function and potentially as therapeutic drugs in metabolic diseases. The first reported and extensively studied FFAR4 specific synthetic agonist was TUG-891 [3-(4-((4-fluoro-4'-methyl-[1,1'-biphenyl]-2-yl)methoxy)phenyl)propanoic acid] [69]. Signaling properties of TUG-891 were comparable to natural agonists of FFAR4 and stimulation of human cells with TUG-891 induced Ca2+ mobilization, recruitment of $\beta$-arrestins and activation of ERK pathway $[67,68]$. TUG-891 was also able to induced phosphorylation of FFAR4 followed by receptor internalization. TUG-891 was able to mimic almost all the beneficial properties of natural agonists of FFAR4 including GLP-1 secretion from enteroendocrine cells, augmenting glucose uptake in murine adipocytes and inhibiting inflammatory mediators from macrophages $[60,66,69]$. TUG-891 was also shown to reduce food intake, enhance insulin signaling and reverse insulin resistance in mice. These results indicate a great promise for TUG-891 as a potential therapeutic molecule for type 2 diabetes and obesity. Several other FFAR4 specific agonists have been developed and shown to have promising anti-diabetic properties $[53,54,70]$. The list of FFAR agonists that have been developed for potential therapeutic value are summarized in table 1 


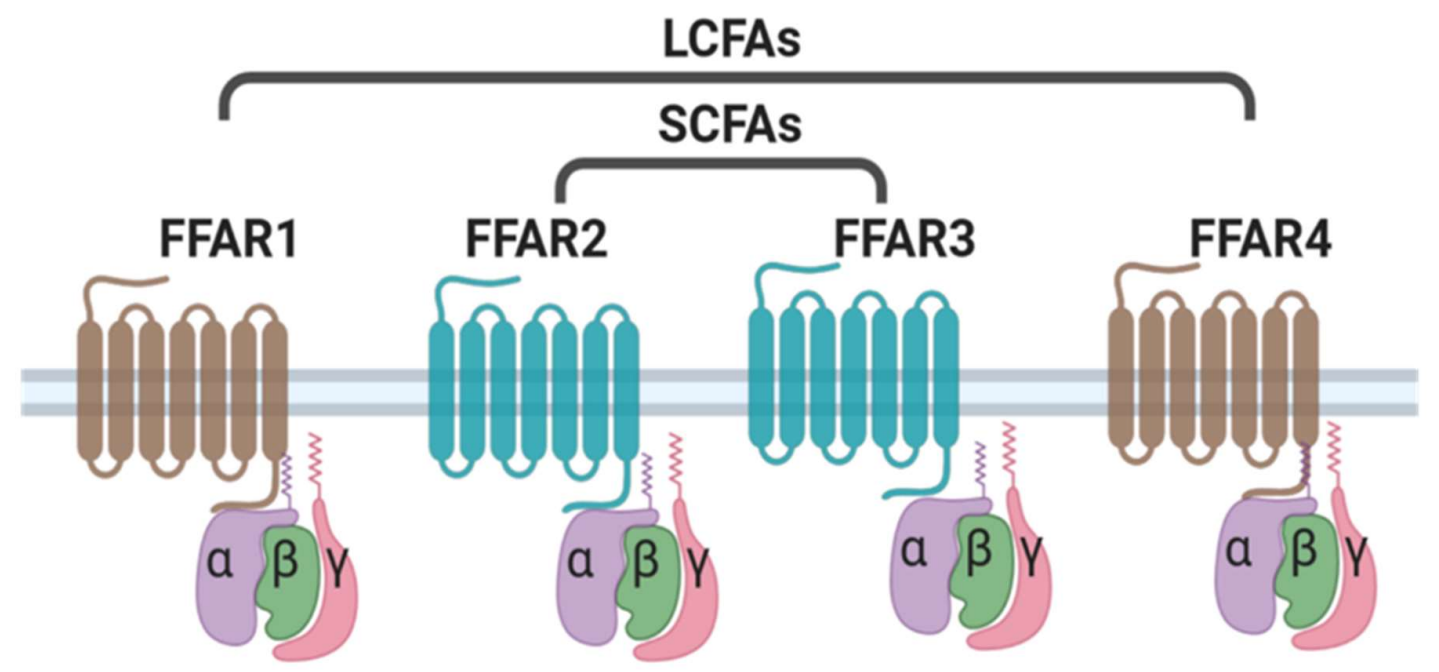

Fig 1. Ligand specificity of Free Fatty acid receptors. FFAR1 and FFAR4 act as receptors for long chain fatty acids (LCFAs), whereas short chain fatty acids (SCFAs) specifically activate FFAR2 and FFAR3. 


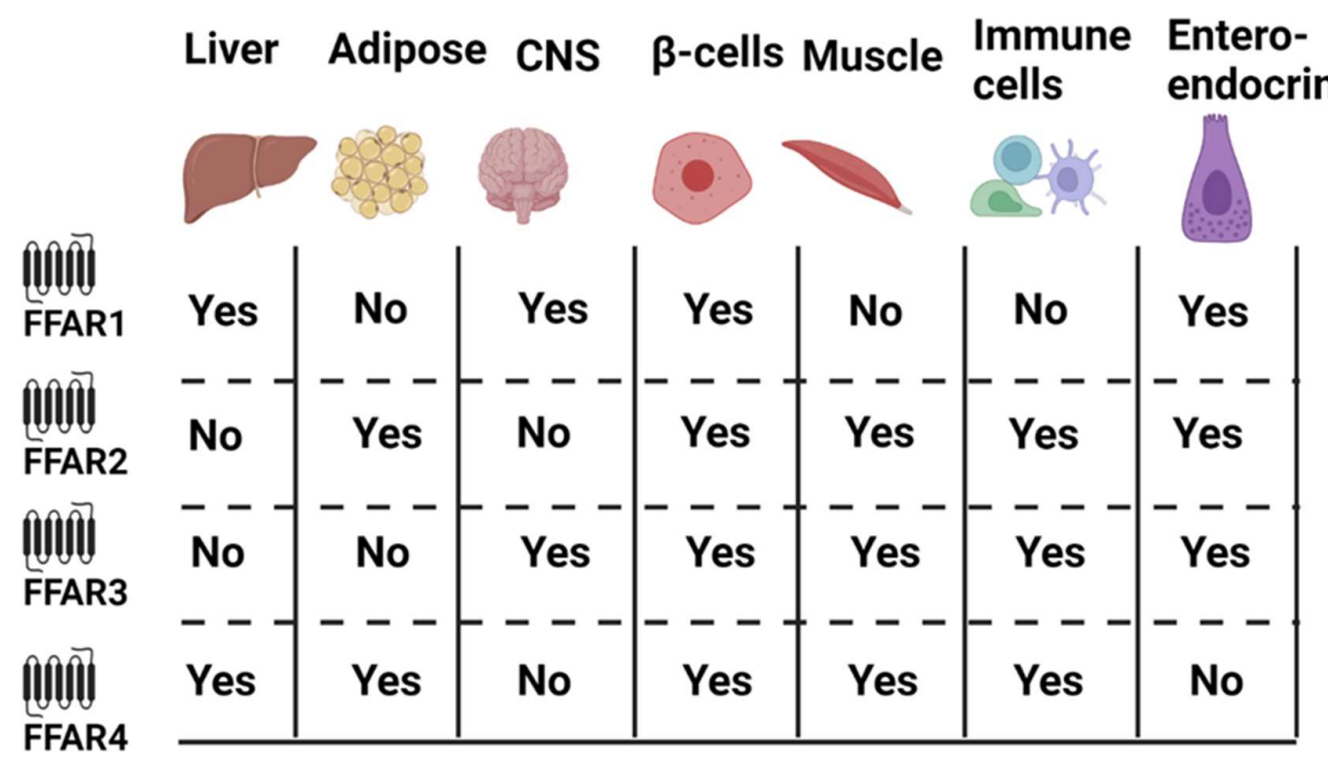

Fig 2. Expression of Free Fatty acid receptors in different body sites

humans

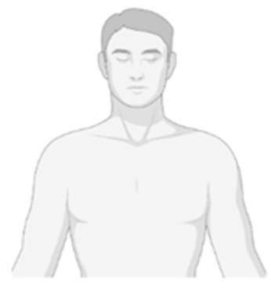

FFAR4 variant $\mathrm{RH} 270$

FFAR4 varian

Pisk of Obesity
and T2DM mice

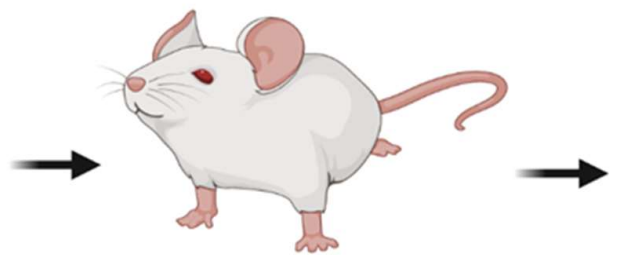

in vitro

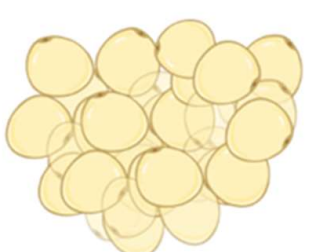

Adipocytes

Ffar4 knockout mice

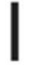

Adipose dysfunction Insulin resistance Metabolic dysregulation
Adipogenesis Insulin sensitivity Thermogenesis Fatty acid Oxidation

Fig.3. Physiological significance of FFAR4 in adipose tissue metabolism. Evidence from human, mouse and in vitro studies 


\begin{tabular}{|c|c|c|c|}
\hline Agonist Name & Target & Physiological Functions & erence \\
\hline TAK-875 & FFAR1 & $\begin{array}{l}\text { Stimulates glucose dependent Insulin secretion and Improves } \\
\text { glycemic control in T2DM patients }\end{array}$ & {$[2]$} \\
\hline AMG837 & FFAR1 & Increases insulin secretion and lowers blood glucose levels in mice & [3] \\
\hline GW-9508 & FFAR1 & Enhances insulin sensitivity and regulates glucose homeostasis & [4] \\
\hline TUG-424 & FFAR1 & Improves glucose tolerance in mice & [5] \\
\hline AM-1638 & FFAR1 & Increases insulin secretion and lowers blood glucose levels in mice & [6] \\
\hline AM-5262 & FFAR1 & $\begin{array}{l}\text { Enhances glucose stimulated insulin secretion (mouse and human } \\
\text { islets) and improves glucose homeostasis in mice }\end{array}$ & {$[7,8]$} \\
\hline LY2881835 & FFAR1 & Stimulates insulin secretion from pancreatic $\beta$-cells & [9] \\
\hline MK-2305 & FFAR1 & $\begin{array}{l}\text { Increases glucose stimulated insulin secretion, resulting in } \\
\text { improvement of glucose homeostasis in the diabetic mice }\end{array}$ & {$[10]$} \\
\hline CMTB & FFAR2 & Inhibits lipolysis in murine adipocytes & [11] \\
\hline TUG-1375 & FFAR2 & $\begin{array}{l}\text { Induces migration of human neutrophils and to inhibit lipolysis in } \\
\text { murine adipocytes. }\end{array}$ & {$[12]$} \\
\hline Compound 1 & FFAR2 & Inhibits lipolysis in murine adipocytes & [13] \\
\hline TUG-891 & FFAR4 & $\begin{array}{l}\text { Stimulates GLP-1 secretion from enteroendocrine cells, enhances } \\
\text { glucose uptake in 3T3-L1 adipocytes, and inhibits release of pro- } \\
\text { inflammatory mediators from RAW } 264.7 \text { macrophages }\end{array}$ & [14] \\
\hline AZ13581837 & FFAR4 & Increases insulin secretion and reduces blood glucose levels in mice & [15] \\
\hline CpdA & FFAR4 & Increases insulin sensitivity and improves glucose tolerance in mice & [16] \\
\hline Metabolex-36 & FFAR4 & Insulin secretagogue with glucose lowering properties & [17] \\
\hline GSK137647 & FFAR4 & Improves glucose tolerance & [18] \\
\hline TUG-1197 & FFAr4 & Enhances insulin sensitivity and reduces bodyweight & [19] \\
\hline NCG21 & FFAR4 & Increases GLP-1 secretion & [20] \\
\hline GW9508 & FFAR4 & Enhances insulin sensitivity and thermogenic activity of adipocytes & {$[21]$} \\
\hline
\end{tabular}

Table 1. List of synthetic agonists of FFAR isoforms and their physiological actions 


\section{Conclusions}

GPCRs represent one of the largest groups of cell surface proteins that are widely expressed throughout the body and regulate nearly every single biological process. A group of GPCRs were identified as receptors for Free Fatty acids and named as FFAR1 (GPR40), FFAR2 (GPR43), FFAR3 (GPR41) and FFAR4 (GPR120). FFARs control many important biological processes including insulin secretion, food intake, adipogenesis, immune cell metabolism and many more. FFAR2 and FFAR4 are highly expressed in human and mouse adipose tissue and have been shown to regulate multiple aspects of adipose metabolism. Consequently, FFARs have attracted considerable attention as pharmacological targets in the treatment of obesity and Type 2 diabetes. Several synthetic agonists of FFARs have been developed and shown to have anti-diabetic effects in preclinical studies. In the coming years several FFAR based drugs are expected to be tested in human clinical trials. While, a lots of work has been done to understand the physiological significance of FFARs in adipose tissue, more work is needed to know the detailed signaling mechanism and physiological functions of FFARs in adipose. A comprehensive understanding of FFARs role in adipogenesis and adipose metabolic functions represents an exciting research opportunity in drug development for the treatment of obesity and type 2 diabetes.

Author Contributions: SM, SAM, SSM, MI, EH and GD searched and scrutinized the literature. SM and SAM wrote the paper. All authors read and approved the final manuscript.

Funding: This study was supported by King Abdullah International Medical Research Center (KAIMRC) through research grant RC16/158/R awarded to SM.

Institutional Review Board Statement: Not applicable.

Informed Consent Statement: Not applicable

Acknowledgments: Figures were created using templates on Biorender (Toronto, Canada)

Conflicts of Interest: The authors declare no conflict of interest

\section{References}

1. Wang, L.; Zhu, L.; Meister, J.; Bone, D.B.J.; Pydi, S.P.; Rossi, M.; Wess, J. Use of DREADD Technology to Identify Novel Targets for Antidiabetic Drugs. Annu. Rev. Pharmacol. Toxicol. 2021.

2. Thompson, M.D.; Siminovitch, K.A.; Cole, D.E.C. G protein-coupled receptor pharmacogenetics. Methods Mol. Biol. 2008, doi:10.1007/978-1-59745-205-2_8.

3. Krishna, S.; Insel, P. GPCRs as targets for approved drugs: How many targets and how many drugs? Mol. Pharmacol. 2018.

4. Hauser, A.S.; Attwood, M.M.; Rask-Andersen, M.; Schiöth, H.B.; Gloriam, D.E. Trends in GPCR drug discovery: New agents, targets and indications. Nat. Rev. Drug Discov. 2017, doi:10.1038/nrd.2017.178.

5. Fredriksson, R.; Lagerström, M.C.; Lundin, L.G.; Schiöth, H.B. The G-protein-coupled receptors in the human genome form five main families. Phylogenetic analysis, paralogon groups, and fingerprints. Mol. Pharmacol. 2003, doi:10.1124/mol.63.6.1256.

6. Hara, T.; Kimura, I.; Inoue, D.; Ichimura, A.; Hirasawa, A. Free fatty acid receptors and their role in regulation of energy metabolism. Rev. Physiol. Biochem. Pharmacol. 2013, doi:10.1007/112_2013_13.

7. Hirasawa, A.; Hara, T.; Ichimura, A.; Tsujimoto, G. Free fatty acid receptors and their physiological role in metabolic regulation. Yakugaku Zasshi 2011.

8. Ichimura, A.; Hirasawa, A.; Hara, T.; Tsujimoto, G. Free fatty acid receptors act as nutrient sensors to regulate energy homeostasis. Prostaglandins Other Lipid Mediat. 2009.

9. V., V.; V., S.; G., J.; B.T., B. Free fatty acid receptors: Emerging targets for treatment of diabetes and its complications. Ther. Adv. Endocrinol. Metab. 2010.

10. Hara, T.; Kashihara, D.; Ichimura, A.; Kimura, I.; Tsujimoto, G.; Hirasawa, A. Role of free fatty acid receptors in the regulation of energy metabolism. Biochim. Biophys. Acta - Mol. Cell Biol. Lipids 2014.

11. Itoh, Y.; Kawamata, Y.; Harada, M.; Kobayashi, M.; Fujii, R.; Fukusumi, S.; Ogi, K.; Hosoya, M.; Tanaka, Y.; Uejima, H.; et al. Free fatty acids regulate insulin secretion from pancreatic $\beta$ cells through GPR40. Nature 2003, doi:10.1038/nature01478. 
12. Hopkins, M.M.; Meier, K.E. Free fatty acid receptors and cancer: From nutrition to pharmacology. In Handbook of Experimental Pharmacology; 2017.

13. Ghislain, J.; Poitout, V. Targeting lipid GPCRs to treat type 2 diabetes mellitus - progress and challenges. Nat. Rev. Endocrinol. 2021.

14. Milligan, G.; Shimpukade, B.; Ulven, T.; Hudson, B.D. Complex pharmacology of free fatty acid receptors. Chem. Rev. 2017.

15. Son, S.E.; Kim, N.J.; Im, D.S. Development of free fatty acid receptor 4 (FFA4/GPR120) agonists in health science. Biomol. Ther. 2021, 29, 22-30, doi:10.4062/BIOMOLTHER.2020.213.

16. Grundmann, M.; Bender, E.; Schamberger, J.; Eitner, F. Pharmacology of free fatty acid receptors and their allosteric modulators. Int. J. Mol. Sci. 2021.

17. Hauser, A.S.; Chavali, S.; Masuho, I.; Jahn, L.J.; Martemyanov, K.A.; Gloriam, D.E.; Babu, M.M. Pharmacogenomics of GPCR Drug Targets. Cell 2018, doi:10.1016/j.cell.2017.11.033.

18. Tomita, T.; Masuzaki, H.; Iwakura, H.; Fujikura, J.; Noguchi, M.; Tanaka, T.; Ebihara, K.; Kawamura, J.; Komoto, I.; Kawaguchi, Y.; et al. Expression of the gene for a membrane-bound fatty acid receptor in the pancreas and islet cell tumours in humans: Evidence for GPR40 expression in pancreatic beta cells and implications for insulin secretion. Diabetologia 2006, doi:10.1007/s00125-006-0193-8.

19. Gorski, J.N.; Pachanski, M.J.; Mane, J.; Plummer, C.W.; Souza, S.; Thomas-Fowlkes, B.S.; Ogawa, A.M.; Weinglass, A.B.; Di Salvo, J.; Cheewatrakoolpong, B.; et al. GPR40 reduces food intake and body weight through GLP-1. Am. J. Physiol. - Endocrinol. Metab. 2017, doi:10.1152/ajpendo.00435.2016.

20. Li, Z.; Xu, X.; Huang, W.; Qian, H. Free Fatty Acid Receptor 1 (FFAR1) as an Emerging Therapeutic Target for Type 2 Diabetes Mellitus: Recent Progress and Prevailing Challenges. Med. Res. Rev. 2018.

21. Del Guerra, S.; Bugliani, M.; D’Aleo, V.; Del Prato, S.; Boggi, U.; Mosca, F.; Filipponi, F.; Lupi, R. G-protein-coupled receptor 40 (GPR40) expression and its regulation in human pancreatic islets: The role of type 2 diabetes and fatty acids. Nutr. Metab. Cardiovasc. Dis. 2010, doi:10.1016/j.numecd.2009.02.008.

22. Hauge, M.; Vestmar, M.A.; Husted, A.S.; Ekberg, J.P.; Wright, M.J.; Di Salvo, J.; Weinglass, A.B.; Engelstoft, M.S.; Madsen, A.N.; Lückmann, M.; et al. GPR40 (FFAR1) - Combined Gs and Gq signaling invitro is associated with robust incretin secretagogue action ex vivo and in vivo. Mol. Metab. 2015, doi:10.1016/j.molmet.2014.10.002.

23. Edfalk, S.; Steneberg, P.; Edlund, H. Gpr40 is expressed in enteroendocrine cells and mediates free fatty acid stimulation of incretin secretion. Diabetes 2008, doi:10.2337/db08-0307.

24. Mohammad, S. GPR40 Agonists for the Treatment of Type 2 Diabetes Mellitus: Benefits and Challenges. Curr. Drug Targets 2016, doi:10.2174/1389450117666151209122702.

25. Kimura, I.; Inoue, D.; Hirano, K.; Tsujimoto, G. The SCFA receptor GPR43 and energy metabolism. Front. Endocrinol. (Lausanne). 2014.

26. Bindels, L.B.; Dewulf, E.M.; Delzenne, N.M. GPR43/FFA2: Physiopathological relevance and therapeutic prospects. Trends Pharmacol. Sci. 2013.

27. Kimura, I.; Ichimura, A.; Ohue-Kitano, R.; Igarashi, M. Free fatty acid receptors in health and disease. Physiol. Rev. 2020, doi:10.1152/physrev.00041.2018.

28. Inoue, D.; Tsujimoto, G.; Kimura, I. Regulation of energy homeostasis by GPR41. Front. Endocrinol. (Lausanne). 2014.

29. Mishra, S.P.; Karunakar, P.; Taraphder, S.; Yadav, H. FFAR2/3 as Microbial Metabolite Sensors to Shape Host Health: Pharmacophysiological View. Not Publ. yet 2020.

30. Halder, S.; Kumar, S.; Sharma, R. The therapeutic potential of GPR120: A patent review. Expert Opin. Ther. Pat. 2013.

31. Zhang, D.; Leung, P.S. Potential roles of GPR120 and its agonists in the management of diabetes. Drug Des. Devel. Ther. 2014.

32. Karakuła-Juchnowicz, H.; Róg, J.; Juchnowicz, D.; Morylowska-Topolska, J. GPR120: Mechanism of action, role and potential for medical applications. Postepy Hig. Med. Dosw. (Online) 2017.

33. Ge, H.; Li, X.; Weiszmann, J.; Wang, P.; Baribault, H.; Chen, J.-L.; Tian, H.; Li, Y. Activation of G Protein-Coupled Receptor 43 in Adipocytes Leads to Inhibition of Lipolysis and Suppression of Plasma Free Fatty Acids. Endocrinology 2008, 149, 4519-4526, doi:10.1210/EN.2008-0059.

34. YH, H.; Y, N.; D, H.; H, T.; H, M.; C, G.; KC, C.; DD, F.; C, C.; HG, L.; et al. Acetate and propionate short chain fatty acids stimulate adipogenesis via GPCR43. Endocrinology 2005, 146, 5092-5099, doi:10.1210/EN.2005-0545.

35. Zaibi, M.S.; Stocker, C.J.; O’Dowd, J.; Davies, A.; Bellahcene, M.; Cawthorne, M.A.; Brown, A.J.H.; Smith, D.M.; Arch, J.R.S. Roles of GPR41 and GPR43 in leptin secretory responses of murine adipocytes to short chain fatty acids. FEBS Lett. 2010, 584, 2381-2386, doi:10.1016/J.FEBSLET.2010.04.027.

36. Dewulf, E.M.; Ge, Q.; Bindels, L.B.; Sohet, F.M.; Cani, P.D.; Brichard, S.M.; Delzenne, N.M. Evaluation of the relationship between GPR43 and adiposity in human. Nutr. Metab. 2013, doi:10.1186/1743-7075-10-11.

37. Frost, G.; Cai, Z.; Raven, M.; Otway, D.T.; Mushtaq, R.; Johnston, J.D. Effect of short chain fatty acids on the expression of free fatty acid receptor 2 (Ffar2), Ffar3 and early-stage adipogenesis. Nutr. Diabetes 2014, doi:10.1038/nutd.2014.25.

38. Iván, J.; Major, E.; Sipos, A.; Kovács, K.; Horváth, D.; Tamás, I.; Bay, P.; Dombrádi, V.; Lontay, B. The Short-Chain Fatty Acid Propionate Inhibits Adipogenic Differentiation of Human Chorion-Derived Mesenchymal Stem Cells Through the Free Fatty Acid Receptor 2. Stem Cells Dev. 2017, 26, 1724, doi:10.1089/SCD.2017.0035. 
39. Lee, T.; Schwandner, R.; Swaminath, G.; Weiszmann, J.; Cardozo, M.; Greenberg, J.; Jaeckel, P.; Ge, H.; Wang, Y.; Jiao, $\mathrm{X}$; et al. Identification and functional characterization of allosteric agonists for the G protein-coupled receptor FFA2. Mol. Pharmacol. 2008, doi:10.1124/mol.108.049536.

40. Wang, Y.; Jiao, X.; Kayser, F.; Liu, J.; Wang, Z.; Wanska, M.; Greenberg, J.; Weiszmann, J.; Ge, H.; Tian, H.; et al. The first synthetic agonists of FFA2: Discovery and SAR of phenylacetamides as allosteric modulators. Bioorganic Med. Chem. Lett. 2010, doi:10.1016/j.bmcl.2009.11.112.

41. Ang, Z.; Ding, J.L. GPR41 and GPR43 in obesity and inflammation - Protective or causative? Front. Immunol. 2016.

42. Tolhurst, G.; Heffron, H.; Lam, Y.S.; Parker, H.E.; Habib, A.M.; Diakogiannaki, E.; Cameron, J.; Grosse, J.; Reimann, F.; Gribble, F.M. Short-chain fatty acids stimulate glucagon-like peptide-1 secretion via the G-protein-coupled receptor FFAR2. Diabetes 2012, doi:10.2337/db11-1019.

43. Kimura, I.; Ozawa, K.; Inoue, D.; Imamura, T.; Kimura, K.; Maeda, T.; Terasawa, K.; Kashihara, D.; Hirano, K.; Tani, T.; et al. The gut microbiota suppresses insulin-mediated fat accumulation via the short-chain fatty acid receptor GPR43. Nat. Commun. 2013, doi:10.1038/ncomms2852.

44. Bjursell, M.; Admyre, T.; Göransson, M.; Marley, A.E.; Smith, D.M.; Oscarsson, J.; Bohlooly-Y, M. Improved glucose control and reduced body fat mass in free fatty acid receptor 2-deficient mice fed a high-fat diet. Am. J. Physiol. - Endocrinol. Metab. 2011, doi:10.1152/ajpendo.00229.2010.

45. Ichimura, A.; Hirasawa, A.; Poulain-Godefroy, O.; Bonnefond, A.; Hara, T.; Yengo, L.; Kimura, I.; Leloire, A.; Liu, N.; Iida, K.; et al. Dysfunction of lipid sensor GPR120 leads to obesity in both mouse and human. Nature 2012, doi:10.1038/nature10798.

46. Satapati, S.; Qian, Y.; Wu, M.S.; Petrov, A.; Dai, G.; Wang, S.P.; Zhu, Y.; Shen, X.; Muise, E.S.; Chen, Y.; et al. GPR120 suppresses adipose tissue lipolysis and synergizes with GPR40 in antidiabetic efficacy. J. Lipid Res. 2017, doi:10.1194/jlr.M075044.

47. Oh, D.Y.; Talukdar, S.; Bae, E.J.; Imamura, T.; Morinaga, H.; Fan, W.Q.; Li, P.; Lu, W.J.; Watkins, S.M.; Olefsky, J.M. GPR120 Is an Omega-3 Fatty Acid Receptor Mediating Potent Anti-inflammatory and Insulin-Sensitizing Effects. Cell 2010, doi:10.1016/j.cell.2010.07.041.

48. Liu, D.; Wang, L.; Meng, Q.; Kuang, H.; Liu, X. G-protein coupled receptor 120 is involved in glucose metabolism in fat cells. Cell. Mol. Biol. (Noisy-le-grand). 2012.

49. Song, T.; Yang, Y.; Zhou, Y.; Wei, H.; Peng, J. GPR120: a critical role in adipogenesis, inflammation, and energy metabolism in adipose tissue. Cell. Mol. Life Sci. 2017.

50. Oh, D.Y.; Walenta, E.; Akiyama, T.E.; Lagakos, W.S.; Lackey, D.; Pessentheiner, A.R.; Sasik, R.; Hah, N.; Chi, T.J.; Cox, J.M.; et al. A Gpr120-selective agonist improves insulin resistance and chronic inflammation in obese mice. Nat. Med. 2014, doi:10.1038/nm.3614.

51. Wang, Y.M.; Liu, H.X.; Fang, N.Y. 9-PAHSA promotes browning of white fat via activating G-protein-coupled receptor 120 and inhibiting lipopolysaccharide / NF-kappa B pathway. Biochem. Biophys. Res. Commun. 2018, 506, 153-160, doi:10.1016/J.BBRC.2018.09.050.

52. Quesada-López, T.; Gavalda-Navarro, A.; Morón-Ros, S.; Campderrós, L.; Iglesias, R.; Giralt, M.; Villarroya, F. GPR120 controls neonatal brown adipose tissue thermogenic induction. Am. J. Physiol. Endocrinol. Metab. 2019, 317, E742-E750, doi:10.1152/AJPENDO.00081.2019.

53. Schilperoort, M.; Dam, A.D.; Hoeke, G.; Shabalina, I.G.; Okolo, A.; Hanyaloglu, A.C.; Dib, L.H.; Mol, I.M.; Caengprasath, N.; Chan, Y.; et al. The GPR 120 agonist TUG -891 promotes metabolic health by stimulating mitochondrial respiration in brown fat . EMBO Mol. Med. 2018, 10, doi:10.15252/emmm.201708047.

54. Christian, M. Elucidation of the roles of brown and brite fat genes: GPR120 is a modulator of brown adipose tissue function. Exp. Physiol. 2020, 105, 1201-1205, doi:10.1113/EP087877.

55. Quesada-López, T.; Cereijo, R.; Turatsinze, J.V.; Planavila, A.; Cairó, M.; Gavaldà-Navarro, A.; Peyrou, M.; Moure, R.; Iglesias, R.; Giralt, M.; et al. The lipid sensor GPR120 promotes brown fat activation and FGF21 release from adipocytes. Nat. Commun. 2016, 7, doi:10.1038/NCOMMS13479.

56. Bonnefond, A.; Lamri, A.; Leloire, A.; Vaillant, E.; Roussel, R.; Lévy-Marchal, C.; Weill, J.; Galan, P.; Hercberg, S.; Ragot, S.; et al. Contribution of the low-frequency, loss-of-function p. R270H mutation in FFAR4 (GPR120) to increased fasting plasma glucose levels. J. Med. Genet. 2015, doi:10.1136/jmedgenet-2015-103065.

57. Lamri, A.; Bonnefond, A.; Meyre, D.; Balkau, B.; Roussel, R.; Marre, M.; Froguel, P.; Fumeron, F. Interaction between GPR120 p.R270H loss-of-function variant and dietary fat intake on incident type 2 diabetes risk in the D.E.S.I.R. study. Nutr. Metab. Cardiovasc. Dis. 2016, doi:10.1016/j.numecd.2016.04.010.

58. Stoddart, L.A.; Smith, N.J.; Milligan, G. International union of pharmacology. LXXI. Free fatty acid receptors FFA1, -2, and -3: Pharmacology and pathophysiological functions. Pharmacol. Rev. 2008.

59. Hirasawa, A.; Hara, T.; Katsuma, S.; Adachi, T.; Tsujimoto, G. Free fatty acid receptors and drug discovery. Biol. Pharm. Bull. 2008.

60. Carullo, G.; Mazzotta, S.; Vega-Holm, M.; Iglesias-Guerra, F.; Manuel Vega-Pérez, J.; Aiello, F.; Brizzi, A. GPR120/FFAR4 Pharmacology: Focus on Agonists in Type 2 Diabetes Mellitus Drug Discovery. Cite This J. Med. Chem 2021, 64, 4332, doi:10.1021/acs.jmedchem.0c01002. 
61. Burant, C.F.; Viswanathan, P.; Marcinak, J.; Cao, C.; Vakilynejad, M.; Xie, B.; Leifke, E. TAK-875 versus placebo or glimepiride in type 2 diabetes mellitus: A phase 2, randomised, double-blind, placebo-controlled trial. Lancet 2012, doi:10.1016/S0140-6736(11)61879-5.

62. Arora, A.; Behl, T.; Sehgal, A.; Singh, S.; Sharma, N.; Chigurupati, S.; Kaur, R.; Bhatia, S.; Al-Harrasi, A.; Vargas-De-LaCruz, C.; et al. Free fatty acid receptor 1: a ray of hope in the therapy of type 2 diabetes mellitus. Inflammopharmacology 2021.

63. Smith, N.J.; Ward, R.J.; Stoddart, L.A.; Hudson, B.D.; Kostenis, E.; Ulven, T.; Morris, J.C.; Tränkle, C.; Tikhonova, I.G.; Adams, D.R.; et al. Extracellular loop 2 of the free fatty acid receptor 2 mediates allosterism of a phenylacetamide agoallosteric modulator. Mol. Pharmacol. 2011, doi:10.1124/mol.110.070789.

64. Hudson, B.D.; Due-Hansen, M.E.; Christiansen, E.; Hansen, A.M.; Mackenzie, A.E.; Murdoch, H.; Pandey, S.K.; Ward, R.J.; Marquez, R.; Tikhonova, I.G.; et al. Defining the molecular basis for the first potent and selective orthosteric agonists of the FFA2 free fatty acid receptor. J. Biol. Chem. 2013, doi:10.1074/jbc.M113.455337.

65. Hansen, A.H.; Sergeev, E.; Bolognini, D.; Sprenger, R.R.; Ekberg, J.H.; Ejsing, C.S.; McKenzie, C.J.; Rexen Ulven, E.; Milligan, G.; Ulven, T. Discovery of a Potent Thiazolidine Free Fatty Acid Receptor 2 Agonist with Favorable Pharmacokinetic Properties. J. Med. Chem. 2018, doi:10.1021/acs.jmedchem.8b00855.

66. Hudson, B.D.; Shimpukade, B.; Mackenzie, A.E.; Butcher, A.J.; Pediani, J.D.; Christiansen, E.; Heathcote, H.; Tobin, A.B.; Ulven, T.; Milligan, G. The Pharmacology of a Potent and Selective Agonist, TUG-891, Demonstrates Both Potential Opportunity and Possible Challenges to Therapeutic Agonism of FFA4 (GPR120). Mol. Pharmacol. 2013.

67. Song, T.; Zhou, Y.; Peng, J.; Tao, Y.X.; Yang, Y.; Xu, T.; Peng, J.; Ren, J.; Xiang, Q.; Wei, H. GPR120 promotes adipogenesis through intracellular calcium and extracellular signal-regulated kinase 1/2 signal pathway. Mol. Cell. Endocrinol. 2016, doi:10.1016/j.mce.2016.06.009.

68. Zhao, Y.F.; Li, X.C.; Liang, X.Y.; Zhao, Y.Y.; Xie, R.; Zhang, L.J.; Zhang, X.C.; Chen, C. GPR120 Regulates Pancreatic Polypeptide Secretion from Male Mouse Islets via PLC-Mediated Calcium Mobilization. Endocrinol. (United States) 2020, doi:10.1210/endocr/bqaa157.

69. Bianchini, G.; Nigro, C.; Sirico, A.; Novelli, R.; Prevenzano, I.; Miele, C.; Beguinot, F.; Aramini, A. A new synthetic dual agonist of GPR120/GPR40 induces GLP-1 secretion and improves glucose homeostasis in mice. Biomed. Pharmacother. 2021, doi:10.1016/j.biopha.2021.111613.

70. Hudson, B.D.; Shimpukade, B.; Mackenzie, A.E.; Butcher, A.J.; Pediani, J.D.; Christiansen, E.; Heathcote, H.; Tobin, A.B.; Ulven, T.; Milligan, G. The pharmacology of TUG-891, a potent and selective agonist of the free fatty acid receptor 4 (FFA4/GPR120), demonstrates both potential opportunity and possible challenges to therapeutic agonism. Mol. Pharmacol. 2013, doi:10.1124/mol.113.087783.

71. Tsujihata, Y.; Ito, R.; Suzuki, M.; Harada, A.; Negoro, N.; Yasuma, T.; Momose, Y.; Takeuchi, K. TAK-875, an orally available $G$ protein-coupled receptor 40 /free fatty acid receptor 1 agonist, enhances glucose-dependent insulin secretion and improves both postprandial and fasting hyperglycemia in type 2 diabetic rats. J. Pharmacol. Exp. Ther. 2011, doi:10.1124/jpet.111.183772.

72. Houze, J.B.; Zhu, L.; Sun, Y.; Akerman, M.; Qiu, W.; Zhang, A.J.; Sharma, R.; Schmitt, M.; Wang, Y.; Liu, J.; et al. AMG 837: A potent, orally bioavailable GPR40 agonist. Bioorganic Med. Chem. Lett. 2012, doi:10.1016/j.bmcl.2011.10.118.

73. Ou, H.Y.; Wu, H.T.; Hung, H.C.; Yang, Y.C.; Wu, J.S.; Chang, C.J. Multiple mechanisms of GW-9508, a selective G protein-coupled receptor 40 agonist, in the regulation of glucose homeostasis and insulin sensitivity. Am. J. Physiol. - Endocrinol. Metab. 2013, doi:10.1152/ajpendo.00419.2012.

74. Christiansen, E.; Due-Hansen, M.E.; Urban, C.; Grundmann, M.; Schmidt, J.; Hansen, S.V.F.; Hudson, B.D.; Zaibi, M.; Markussen, S.B.; Hagesaether, E.; et al. Discovery of a potent and selective free fatty acid receptor 1 agonist with low lipophilicity and high oral bioavailability. J. Med. Chem. 2013, doi:10.1021/jm301470a.

75. Brown, S.P.; Dransfield, P.J.; Vimolratana, M.; Jiao, X.; Zhu, L.; Pattaropong, V.; Sun, Y.; Liu, J.; Luo, J.; Zhang, J.; et al. Discovery of AM-1638: A potent and orally bioavailable GPR40/FFA1 full agonist. ACS Med. Chem. Lett. 2012, doi:10.1021/ml300133f.

76. Wang, Y.; Liu, J.; Dransfield, P.J.; Zhu, L.; Wang, Z.; Du, X.; Jiao, X.; Su, Y.; Li, A.R.; Brown, S.P.; et al. Discovery and optimization of potent GPR40 full agonists containing tricyclic spirocycles. ACS Med. Chem. Lett. 2013, doi:10.1021/ml300427u.

77. Chen, Y.; Song, M.; Riley, J.P.; Hu, C.C.; Peng, X.; Scheuner, D.; Bokvist, K.; Maiti, P.; Kahl, S.D.; Montrose-Rafizadeh, C.; et al. A selective GPR40 (FFAR1) agonist LY2881835 provides immediate and durable glucose control in rodent models of type 2 diabetes. Pharmacol. Res. Perspect. 2016, doi:10.1002/prp2.278.

78. Miller, C.; Pachanski, M.J.; Kirkland, M.E.; Kosinski, D.T.; Mane, J.; Bunzel, M.; Cao, J.; Souza, S.; Thomas-Fowlkes, B.; Di Salvo, J.; et al. GPR40 partial agonist MK-2305 lower fasting glucose in the Goto Kakizaki rat via suppression of endogenous glucose production. PLoS One 2017, doi:10.1371/journal.pone.0176182.

79. Sundström, L.; Myhre, S.; Sundqvist, M.; Ahnmark, A.; McCoull, W.; Raubo, P.; Groombridge, S.D.; Polla, M.; Nyström, A.C.; Kristensson, L.; et al. The acute glucose lowering effect of specific GPR120 activation in mice is mainly driven by glucagon-like peptide 1. PLoS One 2017, doi:10.1371/journal.pone.0189060.

80. Holliday, N.D.; Watson, S.J.; Brown, A.J.H. Drug discovery opportunities and challenges at G protein coupled receptors for long chain free fatty acids. Front. Endocrinol. (Lausanne). 2012. 
81. McCloskey, A.G.; Miskelly, M.G.; Flatt, P.R.; McKillop, A.M. Pharmacological potential of novel agonists for FFAR4 on islet and enteroendocrine cell function and glucose homeostasis. Eur. J. Pharm. Sci. 2020, doi:10.1016/j.ejps.2019.105104.

82. Azevedo, C.M.G.; Watterson, K.R.; Wargent, E.T.; Hansen, S.V.F.; Hudson, B.D.; Kępczyńska, M.A.; Dunlop, J.; Shimpukade, B.; Christiansen, E.; Milligan, G.; et al. Non-Acidic Free Fatty Acid Receptor 4 Agonists with Antidiabetic Activity. J. Med. Chem. 2016, doi:10.1021/acs.jmedchem.6b00685.

83. Sun, Q.; Hirasawa, A.; Hara, T.; Kimura, I.; Adachi, T.; Awaji, T.; Ishiguro, M.; Suzuki, T.; Miyata, N.; Tsujimoto, G. Structure-activity relationships of GPR120 agonists based on a docking simulation. Mol. Pharmacol. 2010, doi:10.1124/mol.110.066324. 